\title{
Mulheres em conflito com a lei: a ressignificação de identidades de gênero em um contexto prisional ${ }^{1}$
}

\author{
Women in conflict with the law: \\ the ressignification of gender identities \\ in a female prison
}

Erika Patrícia Teixeira de Oliveira*

Universidade Estadual de Maringá (Paraná) - UEM

\begin{abstract}
RESUMO: Este artigo apresenta resultados de uma investigação sobre identidades de gênero, ressignificadas por mulheres encarceradas em um presídio feminino do norte do Paraná. As análises realizadas de dados de entrevistas semi-estruturadas revelam que, a partir da sua inserção na cultura prisional, é possível identificar identidades negociadas, desejadas e / ou negadas por essas mulheres e possíveis conflitos de identidade gerados pela relação de suas realidades e culturas, por serem provenientes de classe baixa, oriundas de famílias desestruturadas, com pouca escolaridade e marcadas pelo estigma, de presidiárias. A análise mostra também que as identidades reconstruídas nesse ambiente reforçam a construção de estigmas que contribuem para a reincidência. Concluímos que a prisão deve ser repensada como um espaço para a aplicação da inclusão, reabilitação e reinserção social, por meio de projetos nos quais a escrita deveria ser incluída, considerando o papel social que ela já tem nesse contexto.
\end{abstract}

PALAVRAS-CHAVE: identidades, representações sociais, gênero, escrita.

ABSTRACT: This paper presents the results of an investigation about the ressignification process of gender identities by imprisoned women in a female prison, in the North of Paraná State - South Brazil. The data analyses of semistructured interviews showed that is possible to identify negotiated, desired or negated identities as well as identity conflicts caused by their own realities and

\footnotetext{
${ }^{1}$ Este texto é resultante da minha dissertação de mestrado "Mulheres em conflito com a lei: representações sociais, identidades de gênero e letramento", orientada pela Professora Doutora Neiva Maria Jung. Para detalhamentos sobre quaisquer aspectos aqui apresentados, remeto o leitor ao trabalho original, disponível em: $<$ http://www.ple.uem.br/defesas/def_erika.htm>.

* erikapto@yahoo.com.br
} 
cultures, lower-socio-economic level, dysfunctional families, low literacy level, besides prison stigma. The analyses show that representations and identities rebuilt in the prison environment, especially those of prison and society, reinforce the construction of stigmas which may contribute to create reoccurring imprisonments. Prisons should be revaluated as a place for inclusion, social rehabilitation and re-insertion intro society through specific projects, in which writing should be included, considering it's social role in this context.

KEYWORDS: identities, social representation, gender, writing.

\section{Introdução}

A população carcerária feminina tem crescido consideravelmente nas últimas décadas. Os dados mais atualizados disponibilizados pelo Sistema Integrado de Informação Penitenciária (Infopen) apontam que, em 2002, o número de mulheres presas era de 10.285. Cinco anos depois, em 2007, esse número passou para 25.909. Somado a isso, os presídios brasileiros apresentam problemas como a superlotação, a falta de estrutura física, o fracasso na recuperação e reinserção da população carcerária e a falta de políticas direcionadas às mulheres inseridas no sistema prisional.

Algumas vezes, o descaso é percebido em noticiários, como foi o caso, de grande repercussão, da jovem colocada em uma mesma cela com homens e que era obrigada a manter relaçóes sexuais em troca de comida. Mas, na maioria das vezes, as condiçóes sub-humanas vividas por mulheres e homens encarcerados também ficam aprisionadas dentro das celas, longe dos olhos da sociedade.

Geralmente, ao abordarem a questão relativa à prisão no Brasil, os meios de comunicação não questionam as bases multicausais da violência e nem os problemas do sistema carcerário atual, como a falta de investimento, o sucateamento e o desrespeito ao ser humano; ao contrário disso, estigmatizam ainda mais os já marginalizados.

Consequentemente, a sociedade se esquece das condições socioeconômicas, dos contextos culturais e educacionais que precederam a entrada da pessoa no mundo do crime, direcionando uma culpa individual à pessoa condenada. Nesse sentido, observa-se que a prisão torna-se uma instituição de sequestros: sequestrase não só a liberdade ambulatória dos homens e das mulheres que a ela são submetidos como também a voz, a identidade, a dignidade, a condição de sujeitos e de cidadãos. A prisão é ainda uma instituição de (in)visibilidade: seus muros demarcam as fronteiras entre os que ali estão para serem vigiados e, ao mesmo tempo, tornam esses invisíveis para os demais (ESPINOZA, 2004). 
Homens e mulheres aprisionados em instituições penais estão invisíveis para a sociedade. Mas destacamos que a invisibilidade das mulheres presidiárias torna-se dupla: como presa e como mulher, em vista da diferença numérica pois estão em menor número se comparado à população carcerária masculina; e também pela diferença de gênero. Um exemplo disso é que a maioria das instituições foram projetadas e construídas para os homens. Entretanto, mesmo que nosso enfoque esteja em torno das mulheres presidiárias, não deixamos de considerar que ambas as populações (homens e mulheres) carecem de políticas públicas.

Desse modo, verifica-se que esse problema social aponta a necessidade de se realizar estudos que extrapolem o âmbito jurídico. No que diz respeito ao universo prisional, os estudos sobre as instituiçôes femininas não são muito usuais, sobretudo nas áreas humanas e sociais, o que causa certa invisibilidade da mulher encarcerada. Diante dessa realidade, este artigo pretende contribuir com o desvelamento da mulher presidiária e diminuir a invisibilidade da mulher encarcerada, pela da escuta de suas vozes e do que elas têm a dizer.

Desse modo, o objetivo é reconhecer as identidades sociais de gênero ressignificadas por mulheres encarceradas em um presídio feminino do norte do Paraná. Para alcançar esse objetivo, serão analisados dados de entrevistas com dez mulheres. A partir do conteúdo de suas falas, refletiremos sobre quais identidades sociais são constituídas, para pensar sobre o papel social que a escrita pode ter na reabilitação e reinserção dessas mulheres.

Em termos teórico-metodológicos, entendemos, neste trabalho, que é na e através da linguagem que se formam e se veiculam as representaçôes e as identidades socias. Por isso, articulamos o conceito de representaçôes sociais com um conceito de identidade de cunho ou base antropológica, a fim de compreender, através da linguagem, quais representações e identidades orientam a vida dessas mulheres detentas.

\section{Trabalho de campo: quando as grades foram abertas}

Como se trata de um contexto de pesquisa complexo, visto que as participantes estão reclusas em uma instituição penal, a preparação que antecedeu o trabalho de campo exigiu muito cuidado.

Sendo assim, seguimos alguns encaminhamentos prévios, recomendados por Erickson (1989) e que poderiam ajudar a estabelecer uma relação de confiança: a) procuramos adquirir o maior conhecimento possível a respeito 
das relações interpessoais, a fim de evitar conflitos; b) apresentamos às participantes, sempre que necessário, os objetivos da pesquisa; c) deixamos claro que as gravaçôes e o conteúdo das entrevistas seriam usados somente com o devido consentimento das participantes; d) explicamos que seus nomes seriam substituídos por nomes fictícios.

Durante o tempo em que realizamos o trabalho de campo, havia aproximadamente trinta e três mulheres detidas. A seleção das detentas a serem entrevistadas não seguiu um critério rígido, pré-determinado. Tínhamos como ideia inicial priorizar as que eram ou haviam sido casadas, as que tinham filhos e as que demonstrassem interesse em conversar, pois essas pessoas contavam com uma privação a mais por serem mães e estarem longe de seus filhos, consequentemente, poderiam estar mais abertas para o diálogo, pela necessidade de desabafar. Além disso, acreditávamos que a nossa identidade de mãe, compartilhada com essas mulheres, facilitaria a identificação e aproximação com as participantes.

Durante o trabalho de campo, todavia, outras características das participantes nos chamaram a atenção para a seleção das entrevistadas.

A primeira entrevistada, Paula, havia concedido entrevista a um jornal local e isso despertou nosso interesse. A segunda entrevistada, Dona Nanci, além de também ter participado da reportagem do jornal, possuía a característica de ser líder dentro do presídio, o que levamos em consideração pela "autorização" que esta entrevista nos daria para as que se seguiriam. A terceira participante, Lúcia, chamou nossa atenção pelo fato de estar com câncer no seio e por ter sido mencionada como alguém que assumiu a culpa no lugar do filho. Silvana e Graciela, por serem mãe e filha. Taís, Josiani e Rosa, por serem casadas e terem filhos. Júlia foi selecionada pela simpatia que sempre demonstrou ao nos ver; e Liliane, por estar com um bebê e demonstrar interesse em conceder a entrevista.

Privilegiamos, neste trabalho, a entrevista semi-estruturada. A partir do eixo temático deste estudo, elaboramos um roteiro com 27 perguntas, que tinham como preocupações centrais evitar induzir as respostas das participantes e abordar aspectos relacionados com suas representaçôes sociais acerca do gênero feminino, do presídio, da sociedade, da família e da escola.

As entrevistas aconteceram no consultório odontológico, único local considerado seguro e possível pelos funcionários, e sem muita interferência sonora. 
Foram realizadas entrevistas individuais, com dez participantes, no período de 13/06/2007 a 18/01/2008. Quando finalizamos o trabalho de campo, iniciamos a transcrição das fitas, que resultou em 101 páginas de transcrição.

Neste trabalho, a transcrição constitui uma tentativa de representar em texto o conteúdo da interação gravada, e não a ação dos sujeitos durante a interação. Nesta transcrição, optamos por privilegiar a forma escrita culta, visto que: a) o foco da nossa pesquisa não está nas variações fonológicas, morfológicas ou sintáticas; b) consideramos que uma transcrição que levasse em conta as características do discurso oral tornaria o texto transcrito de difícil leitura; ec) poderia reforçar estereótipos, através da ideia de que a linguagem culta pertence aqueles que se encontram em situação privilegiada e as variedades dialetais aqueles que estão em situação desprivilegiada socialmente (SIGNORINI, 2006).

Consideramos importante destacar que, durante este trabalho de campo, buscou-se manter com as participantes uma relação de empatia e confiança, para que, a partir dessa relação, pudéssemos obter informações a respeito de uma realidade que só quem vivencia pode oferecer.

\section{Identidade Social: gênero e diferença}

A questão da identidade social é abordada por diversas correntes e perspectivas teóricas. A Antropologia, a Sociologia, a Psicologia Social e Clínica, a Linguística, os Estudos Culturais são algumas das áreas que desenvolveram e desenvolvem conceitos - alguns deles divergentes - que têm sido utilizados para a reflexão e compreensão do sujeito e sua relação com diferentes aspectos da vida, como no âmbito individual, cultural, econômico, profissional, educacional, institucional, social, entre outros.

A variedade de teorias, conceitos e âmbitos que envolvem a questão demonstram o quão complexo é o estudo sobre o sujeito. Essa complexidade pode ser frutífera na realização de estudos sobre a identidade a partir de uma perspectiva transdisciplinar coerente.

$\mathrm{Na}$ discussão a seguir, sobre identidade social, pretendemos deixar claro em quais perspectivas conceituais este trabalho busca subsídios para compreender as representações e identidades sociais evidenciadas nos discursos de algumas mulheres detentas.

Inicialmente, nos posicionamos a partir dos Estudos Culturais (HALL, 2000), que desenvolvem argumento contrário à visão essencialista, segundo 
a qual a identidade é unificada, fixa e imutável. De acordo com Hall, as identidades pós-modernas são descentradas, deslocadas e fragmentadas.

Para o autor, o conceito de sujeito unificado e centrado, fruto de uma visão essencialista, transformou-se em uma visão de sujeito descentrado e fragmentado em virtude da mudança estrutural das sociedades modernas. Seu argumento segue uma linha histórica, por isso, o autor sugere três concepções de sujeito.

A primeira concepção - o sujeito do iluminismo - está baseada em uma concepção individualista de pessoa humana como um sujeito totalmente centrado, unificado, dotado de razão, de consciência e de ação, situado no centro do conhecimento e da razão.

Na segunda concepção - o sujeito sociológico - a identidade do sujeito é constituída por uma estrutura social e preenche o espaço entre o "interior" e o "exterior" - entre o mundo pessoal e o mundo público, "costurando" o indivíduo à estrutura, promovendo uma maior reciprocidade entre eles, tornando-os mais unificados e previsíveis.

Já o sujeito da pós-modernidade ${ }^{2}$ não tem uma identidade fixa, essencial ou permanente. A visão de um sujeito com identidade unificada e estável, ou como resultado da interação social, dá espaço para que se efetive o surgimento de um sujeito fragmentado, que se compõe, não apenas por uma identidade, mas, sim, por diversas identidades, às vezes contraditórias e desestabilizadas. A identidade torna-se, segundo essa terceira concepção,

uma celebração móvel: formada e transformada continuamente em relação às formas pelas quais somos representados ou interpelados nos sistemas culturais que nos rodeiam. Este sujeito está isento de identidade fixa e permanente, sendo constituído por meio de uma identidade definida historicamente, formada e transformada continuamente (HALL, 2000, p. 13).

Dentro dessa visão não-essencialista, Woodward (2007) acredita que as identidades são fabricadas por meio da marcação da diferença, que ocorre tanto

\footnotetext{
${ }^{2}$ Hall denomina este momento contemporâneo da modernidade como a "pósmodernidade”. Dentre vários intelectuais do século 21, há a ideia de que este século marcou um rompimento em relação à Modernidade. A discussão é longa, mas para alguns, como para Hall, a cisão seria tão profunda que estaríamos vivenciando um período que classificam de "Pós-Modernidade".
} 
por meio de sistemas simbólicos, os quais distinguem o sagrado do profano, o limpo do sujo, quanto por meio de formas de exclusão social.

A partir dessa relação: identidade e diferença, Woodward (2007) analisa o pensamento que se baseia em oposiçóes binárias tais como natureza / cultura e sexo / gênero, mostrando que os termos que formam esses dualismos recebem, na verdade, pesos desiguais, estando estreitamente vinculados a relações de poder, pois é por meio desses dualismos que as mulheres são construídas como "outras", de forma que as mulheres são apenas aquilo que os homens não são.

Para Hall (2007), as identidades são construídas por meio da diferença e não fora dela. Isso implica o reconhecimento radicalmente perturbador de que é apenas por meio da relação com o Outro, da relação com aquilo que não é, com precisamente aquilo que falta, com aquilo que tem sido chamado de seu exterior constitutivo, que o significado "positivo" de qualquer termo - e, assim, sua "identidade" - pode ser construído.

Para Moita Lopes (2002), por sua vez, pesquisador que se filia com a teoria socioconstrucionista, a noção básica que subjaz a seus conceitos é a natureza social presente no discurso, ou seja, a visão do discurso como uma forma de coparticipação social. "Uma palavra é dirigida a um interlocutor: ela é função deste interlocutor” (BAKHTIN, 1981, p. 12). E é por meio desse processo de construção de significado, no qual o interlocutor é crucial, que as pessoas se tornam conscientes de quem são, construindo suas identidades sociais ao agir no mundo por intermédio da linguagem.

À medida que usamos a linguagem em relação a alguém que, da mesma forma, usa a linguagem em relação a nós, pela natureza dialógica do discurso (BAKHTIN, 1981), construímos o mundo e as pessoas nas circunstâncias culturais, institucionais e históricas nas quais estamos situados, isto é, a natureza constitutiva ou socioconstrucionista do discurso.

De acordo com o autor, três traços têm sido apontados como característicos das identidades sociais: fragmentação, contradição e processo: a) a fragmentação se refere ao fato de as pessoas não terem uma identidade social homogênea; b) por possuir diversas identidades sociais, duas ou mais identidades de uma pessoa podem entrar em contradição, devido às relações de poder existentes na sociedade è̀ posição que essa pessoa ocupa em determinadas práticas sociais. Uma visão não-essencialista das identidades sociais pressupõe que identidades contraditórias coexistam em uma mesma pessoa; c) as identidades não são fixas, elas estão sempre em processo, em construção na e através da linguagem. 
Aprendemos a ser quem somos como mulheres, heterossexuais, negros, professores, etc. nas práticas discursivas em que agimos e que têm, portanto, uma base sócio-histórica e cultural. Uma pessoa pobre não é somente pobre mas também mulher ou homem, heterossexual ou gay / lésbica, negra, parda ou branca, jovem, de meia idade ou idosa.

Segundo Moita Lopes (2002), provavelmente, dois dos aspectos centrais de nossas identidades sociais sejam o gênero e a sexualidade. Com base nessas identidades de gênero e sexualidade, entre outras identidades como classe social, raça, nacionalidade, etc., as pessoas usam a linguagem umas com as outras ao mesmo tempo em que constroem essas identidades.

Para uma compreensão acerca de gênero, Louro (1998), feminista pósestruturalista, entende gênero como constituinte identitário dos sujeitos. Numa aproximação às formulações dos Estudos Culturais, que compreendem os sujeitos como tendo identidades plurais, múltiplas, que se transformam, que não são fixas ou permanentes e que podem ser contraditórias, a autora afirma que o gênero institui identidades para o sujeito, assim como a etnia, a classe, ou a nacionalidade, ou seja, transcende o mero desempenho de papéis.

Auad (2006) ressalta que as relações de gênero, do modo como estão organizadas em nossa sociedade, são uma máquina de produzir desigualdades. As visões naturalistas sobre mulheres, meninas, homens e meninos representam travas para a superação dessa situação. Ao considerar as relações de gênero como socialmente construídas, percebe-se que uma série de características consideradas "naturalmente" femininas ou masculinas corresponde às relaçôes de poder. Essas relações vão ganhando a feição de "naturais" de tanto serem praticadas, contadas e repetidas. Tais características são, na verdade, construídas, ao longo dos anos e dos séculos, segundo o modo como as relaçóes entre o feminino e o masculino foram se engendrando socialmente. Ou seja, as relações de poder entre o masculino e o feminino foram sendo construídas socialmente ao longo da história.

Levar em consideração os estudos do gênero é uma possibilidade a mais para reflexão e percepção das estratégias de poder as quais mulheres e homens estão inseridos. Retomando as palavras de Meyer (2007), estamos, em nossa sociedade, sempre operando a partir de uma identidade que é a norma, que é aceita e legitimada e que se torna, por isso mesmo, quase invisível - a masculinidade branca, heterossexual, de classe média e judaico-cristã. E é a diferença que marca e reduz o indivíduo ou grupos de indivíduos a ela. Por isso, 
promover pesquisa na perspectiva do gênero possibilita não só discutir e repensar nossa inserção social como mulheres e homens e como profissionais da educação, mas pode contribuir, efetivamente, para a construção de uma sociedade mais justa e mais igualitária, não só no que se refere ao gênero, mas em todos os seus níveis e relações (MEYER, 2007, p. 25).

Na próxima seção, discute-se como articular epistêmica e metodologicamente identidade e representação social.

\section{Identidade e Representação Social}

De acordo com Moscovici (1981), a representação social é um conjunto de conceitos, afirmaçôes e explicações originadas na vida cotidiana no curso de comunicaçôes interpessoais e pode ser vista como uma versão contemporânea do senso comum. Para o autor, a representação social é um corpus organizado de conhecimentos e uma das atividades psíquicas graças a qual os homens tornam a realidade física e social inteligível, se inserem num grupo ou numa relação cotidiana de trocas e liberam o poder da sua imaginação (MOSCOVICI, 1981, p. 27-28).

Ao ampliar esse conceito, Jodelet (2001) afirma que a representação social é uma forma de conhecimento, socialmente elaborada e partilhada, com um objetivo prático, e que contribui para a construção de uma realidade comum a um conjunto social. Igualmente designada como saber de senso comum ou ainda saber ingênuo, natural, essa forma de conhecimento é diferenciada, entre outras, do conhecimento científico. Entretanto, é concebida como objeto de estudo tão legítimo quanto este, devido à sua importância na vida social e à elucidação possibilitadora dos processos cognitivos e das interaçôes sociais (JODELET, 2001, p. 22).

Para Andrade (2000), o conceito de representação social tem permitido avanços significativos nos estudos sobre a identidade. A representação social, diferentemente das outras formas de conhecimento, supõe uma relação específica entre o sujeito e o objeto de conhecimento: o indivíduo projeta suas identidades no objeto que representa. Assim sendo, a representação que um sujeito faz de um objeto é um bom indício de suas identidades, assim como as identidades de um sujeito são um bom preditor de suas visões de mundo. Isso significa que suas identidades são uma questão chave na representação de qualquer objeto, ou seja, na estruturação de seu campo de representação. Mais 
especificamente, indivíduos e grupos expressam suas identidades por meio de suas representações. Por isso, "a questão da identidade deve ser considerada central na teoria das representaçôes sociais, fato este de maior importância do ponto de vista teórico-metodológico e do ponto de vista da ação social" (ANDRADE, 2000, p. 145). Neste artigo buscamos realizar essa articulação, ou seja, pela análise das representações sociais, buscamos identificar as identidades sociais negociadas, desejadas e / ou negadas pelas pessoas, e possíveis conflitos de identidade.

\section{Identidades de gênero: ressignificações no contexto prisional}

Nesta seção, pretendemos apresentar as identidades sociais constituídas a partir das representações de gênero das participantes e suas possíveis ressignificaçōes e conflitos identitários em virtude de estarem inseridas em um contexto específico de reclusão. Além disso, analisaremos o papel social da escrita na constituição das identidades dessas mulheres que estão distanciadas do convívio diário com suas famílias e filhos e excluídas da sociedade.

Os conceitos teóricos que norteiam esta pesquisa já sinalizaram para a complexidade do conceito de identidades sociais: "celebração móvel", como tão bem definiu Hall (2000), formada e transformada continuamente em relação às formas pelas quais somos representados ou interpelados nos sistemas culturais que nos rodeiam.

É a partir dessa definição que iniciamos nossa análise, com a afirmativa de que as identidades sociais das participantes estão relacionadas com uma diversidade de representações construídas sobre: mulher, homem, família, maternidade, sociedade, prisão, projetos futuros, ensino, escrita, e que são constituídas por diferentes processos sociais dinâmicos, que precisam ser mais bem compreendidos.

Primeiramente, por meio da análise das entrevistas, pode-se afirmar que, as participantes constroem representaçôes que valorizam a mulher na sociedade, como alguém que vem conquistando o seu espaço, e tentam construir uma identidade feminina em contraste com a mulher de antigamente, que vivia apenas em função dos cuidados da casa e dos filhos. Hoje, ela não é só uma dona de casa, mas, sim, "a pilastra da sociedade, é o pilar, ela que não deixa esse mundão aí desabar". Esta fala de uma das participantes reflete a tentativa dela e das outras de se incluírem nesse grupo de mulheres: guerreiras, heroínas e batalhadoras, que trabalham fora, cuidam dos filhos, da casa, são provedoras e responsáveis pelo sustento da família. 
É possível perceber que as mulheres participantes desta pesquisa reproduzem a representação social de mulher moderna, procurando construir uma identidade feminina não somente a partir de "papéis sociais" específicos que desempenham, mas destacando a autonomia e a independência como traços significativos. Entretanto, ao se igualar a esta figura de mulher contemporânea, mas que assumiu mais atividades e responsabilidades, se consideram "guerreiras", pois há em cada dia uma batalha a vencer:

(1)

Me sinto uma mulher guerreira, apesar de ter feito tudo, porque, olha, não é qualquer mulher que segura, não, uma cadeia dessa não; me sinto uma guerreira. À época em que eu me separei do meu marido, cuidei dos meus filhos sozinha. Sempre trabalhei, sempre tentei me esforçar, sempre quis dar o melhor para os meus filhos (Liliane).

Sabemos que a reflexão gerada pelos estudos culturais sobre a identidade e a diferença busca desfazer a ideia de oposiçōes binárias, que elege uma identidade específica como parâmetro em relaçấo ao qual o outro membro do par é avaliado e hierarquizado. Sabemos também que, na sociedade, em geral, o homem é tido como parâmetro e a mulher se constitui através da sua diferença dele. Mas no caso das participantes, elas procuram desfazer o processo no qual a mulher é desvalorizada, invertendo o sentido comumente empregado pela oposição binária na qual o homem é o padrão valorizado.

Neste sentido, ocorre também a constituição da identidade de mulher pela diferença do homem. Os dados apontam que o homem é considerado machista, infiel, frágil, não cuida dos filhos suficientemente. A mulher, por outro lado, é fiel, forte, cuida dos filhos melhor do que o homem. Ou seja, se constitui enquanto mulher através da marcação da diferença, mas por oposição binária, na qual a mulher é privilegiada e o homem recebe carga negativa.

Além desse processo de diferenciação, há também outro processo, no qual as mulheres se igualam aos homens, o que é exemplificado na fala de outra participante. Dona Nanci afirma que "é no roubo, é no tráfico, é tudo quanto é coisa errada, acho que tá tudo mais ou menos igual assim, tá se igualando homem com mulher", evidenciando realmente que existe uma luta entre homens e mulheres na sociedade e que nessa luta a mulher está tomando ou participando de todas as frentes de trabalho.

Por outro lado, a inferioridade da mulher na relação com o homem também aparece nas entrevistas e constrói identidades marcadas pela desigualdade: 
(2)

São machistas, são, porque é:: você não pode usar, não pode usar aquilo, não pode sair sozinha, entende? Então, é um pouco machista. Tem certas coisas que eles falam e a gente tem que abaixar a cabeça e obedecer e outras coisas que não devemos obedecer, né? (Lúcia).

Essa desigualdade destacada na fala de Lúcia pode ser entendida como um reflexo das práticas sociais patriarcais ainda existentes na nossa sociedade, na qual o homem comanda, dá as ordens, é considerado superior e a mulher obedece.

Essa questão aparece em algumas entrevistas, nas quais o homem é tido como responsável e "mediador" da entrada da mulher na prisão: Liliane assumiu a droga para inocentar o marido; Paula foi detida ao transportar droga ("mula") e ao tentar entrar com droga no presídio masculino; o mesmo ocorreu com Silvana e Graciele; Taís se refere ao fato de o marido estar preso, o que gerou problemas financeiros, que a levou, posteriormente, a traficar; Josiani e Júlia estavam com seus companheiros ao serem detidas; Rosa culpa o ex-marido, que é um viciado.

De acordo com alguns estudos e dados sobre a questão carcerária feminina, a figura masculina geralmente está relacionada com a prisão de mulheres no Brasil, o que engloba o tráfico de drogas (MOKI, 2005). Ao demonstrarem isso, as mulheres entrevistadas procuram assumir a posição de vítimas, e não de criminosas.

Fortes e frágeis, independentes e submissas, ao constituírem identidades fragmentadas e contraditórias (HALL, 2000; MOITA LOPES, 2002), elas partilham dos mesmos aspectos constitutivos de gênero, ou seja, participam dos mesmos processos de subjetivação. Um dos aspectos partilhados dentro do presídio é o aspecto amoroso: elas se sentem magoadas, amarguradas, revoltadas, descrentes no amor de um homem, se sentem abandonadas: "ele me abandonou na cadeia. Eu achei que ele jamais ia me abandonar" (Liliane). Embora se considerem capazes de amar incondicionalmente, não se sentem amadas por seus homens, que as abandonaram na prisão.

Todas essas construções em torno da subjetividade evidenciam a visão não-essencialista das identidades sociais, ou seja, essas mulheres não são pessoas unificadas, mas possuem identidades fragmentadas, que se compõem não por uma, mas, sim, por diversas identidades, às vezes contraditórias e desestabilizadas (HALL, 2000). Por um lado, a identidade de mulher contemporânea, mais capaz que o homem, atuante no mercado de trabalho, forte, competente, capaz, guerreira e, por outro, a identidade de mulher submissa, comandada pelo homem, vítima, desprezada, carente, necessitada da atenção do homem. 
Suas identidades tornam-se ainda mais conflituosas e desestabilizadas quando estão relacionadas com a identidade de mãe. Esses conflitos são gerados pelo estabelecimento do novo vínculo que se instaurou entre filha (presa) e sua mãe ou pelo afastamento entre mãe (presa) e seus filhos, em função da reclusão.

Dona Nanci, por exemplo, quando perguntada sobre o papel da mulher, imediatamente vinculou a figura feminina com a maternidade:

(3)

Como mulher, eu acho que todo mundo tem uma cabeça, não tem como, assim, eu me referindo a mim como mãe, eu me acho uma ótima mãe.

A construção de gênero relativa à boa mãe, protetora, que ama incondicionalmente é valorizada, pois é na identidade de mãe que encontram aceitação e pertencimento social. Por outro lado, a partir das representações sociais ressignificadas em relação à figura da mãe, há identidades que também foram re-constituídas ou estão em conflito em virtude do afastamento dos filhos, devido à prisão. Há dois momentos de fala da participante Liliane $(4,5)$, que são bastante representativos desses conflitos vivenciados pelas internas:

(4)

dificuldades mesmo é de estar longe deles, tem dias que eu me pego assim, sabe, fico "meu Deus, que que eu estou fazendo aqui? Quando que eu vou embora? Que que eu fiz de tão errado? Como que a vida tá sendo tão injusta comigo", longe de casa, longe da família, e minha família não é daqui, ( ), é difícil pros meus filhos vir, meus filhos todos pagam passagem, são em três, né? Tem minha mãe, e assim, por saber que eles estão sem a mãe deles, que até o pai deles, o pai deles até abandonou eles também, ao me abandonar na cadeia, abandonou eles também, tudo na casa da minha mãe.

só que eu mudei muito, eu não sou mais uma mãe carinhosa, não consigo mais dar carinho pros meus filhos, nem quando eles vêm me ver, porque eu sei que eu tô aqui dentro, não tem como eu ficar, assim, dando aquela atenção, aquele carinho, depois vão embora, fica tudo triste. / Meus filhos mudaram muito comigo e eu também mudei muito com eles depois que eu vim presa, então já não consigo mais, assim, olhar as coisas de frente, não consigo mais encarar eles de frente. / Carinho eu sei que não vou poder dar mais, vou ser uma mãe seca, dura. 
Liliane está em conflito, pois acredita que deveria estar desempenhando seu papel de mãe no cuidado e proteção aos filhos, mas, no momento, não cumpre esta função por estar presa. Ao mesmo tempo, mudou e passou a se distanciar de seus filhos depois da prisão, não só fisicamente, mas também afetivamente, não consegue ser uma mãe carinhosa como era antes, por isso se sente uma mãe seca e dura.

O que podemos perceber até aqui é que as mulheres estão ressignificando algumas representações sociais e, consequentemente, vivendo conflitos de identidade. $\mathrm{O}$ contato com as outras mulheres, a sua participação na cultura prisional geram uma reconstrução identitária, visto que as identidades não são nunca singulares, mas multiplamente construídas ao longo de discursos, práticas e posições que podem se articular ou ser antagônicas. Elas têm a ver com a questão da utilização dos recursos da história, da linguagem e da cultura para a produção não daquilo que nós somos, mas daquilo no qual nos tornamos (HALL, 2007).

Essa reconstrução identitária não acontece somente em relação a identidades já constituídas pelas mulheres, como a de mãe mas também em relação a representações hegemônicas que tinham em relação à prisão e à detenta. Suas representaçôes de mulher presidiária foram reconstruídas a partir de sua entrada na prisão e do convívio e interação com suas colegas de cela. A imagem de mulher presidiária, como sendo perigosa, bandida, ladra foi desconstruída. Nesse processo, suas identidades são constituídas a partir da negação dessa representação anterior, que continua bastante presente na sociedade.

As identidades são construídas pela negação e diferença entre o que elas realmente se consideram enquanto mulheres presas e o que a sociedade pensa sobre elas. Neste sentido, uma frase bastante recorrente é a de que são traficantes e não ladras, bandidas e perigosas. Elas argumentam que cometeram ato desviante por necessidade financeira, pelo vício ou por falta de oportunidade. Por isso, constroem a identidade desviante relacionada ao ato de traficar.

(6)

Nós que somos conhecidas como os traficantes, nós não vamos matar, nós não vamos roubar, nós não vamos ofender ninguém. / Eu fui traficante, fiz isso e fiz isso, mas nunca precisei roubar uma agulha de ninguém, eu nunca precisei disso e não vou precisar (Dona Nanci, grifo nosso - indica ênfase na fala da participante) 
(7)

Muitas pessoas falam assim "que nada, põe aquelas mulheres tudo na parede e mete bala". I O povo fala que nós merecemos desprezo, porque (.) eu sei, nós estávamos fazendo errado vendendo droga, traficando, tirando a vida de todo mundo, mas quando a gente tá lá fora a gente não tem essa visão (Lúcia).

A atividade de traficar é diferente da atividade de uma ladra. Para elas, traficar é um trabalho, uma forma de obter retorno financeiro "honestamente", se comparado com o ato de roubar, que é uma atitude desvalorizada no presídio feminino. A fala de Liliane, a seguir, confirma esta asserção:

(8)

Eles não querem saber, vamos supor, eu caí com tráfico, que eu tava numa cela com cinco, cinco que é roubo, acha que eu também vou entrar numa casa pra trabalhar, ou vou, se eu for pegar serviço numa loja, alguma coisa, vão achar que eu vou roubar porque eu tava no meio delas. / Eles olham pra gente como se a gente fosse bicho, a gente é bem maltratado quando sai daqui, pela sociedade (Liliane).

No trecho acima, percebemos três grandes fatores considerados pelas detentas: (a) a diferença (que a sociedade não faz) entre ser traficante e ser ladra; (b) a discriminação contra a presidiária: "eles olham pra gente como se a gente fosse bicho"; (c) a discriminação social gerada pelo estigma de ex-presidiária: "a gente é bem maltratado quando sai daqui, pela sociedade".

Essas representações de que a sociedade é injusta, preconceituosa e não dá oportunidades para quem esteve preso geram identidades desfavoráveis, que levam ao descrédito: ao sair da prisão ela será ex-presidiária, discriminada pela sociedade, não terá oportunidades para reingressar e ser aceita socialmente:

(9)

Já me senti muito discriminada. Foi quando eu fui trabalhar na Casa São Paulo. Foram procurar minha antecedência, viram que eu era uma ex-presidiária. / Foi uma época assim que eu me senti lá embaixo, ele saiu me acompanhando chamou o segurança, saí pela porta do fundo da garagem, não saí pela frente, que é o lugar da gente sair certo. / Eu acho assim que foi a discriminação muito assim que eu tive nessa parte de ser ex-presidiária, é o que a gente vai esperar na rua, é isso, infelizmente é isso que a gente leva da sociedade uma hora (Dona Nanci). 
Há um descompasso entre o que a sociedade pensa sobre elas e a representação que elas constroem para si, mas é mais fácil suas ações serem influenciadas negativamente pelo rótulo e pelo estigma de serem ex-presidiárias e "criminosas":

(10)

Porque se quiser mudança, é só mudando, porque, ao contrário, sempre continua no erro, sempre, porque todo momento você tá ali, você tá sendo negada, você bate na porta, você:: bate a porta na sua cara, você entendeu? Então:: aí o que acontece? É onde volta fazer coisas erradas. Então eu acho que, quando a gente sai pra fora, a gente tem que mudar, porque a sociedade não aceita, tem muitas pessoas que não aceitam, discrimina. (Liliane, grifo nosso).

Nessa relação conflituosa entre indivíduo e sociedade, o que se reforça éa identidade socialmente construída, o que gera consequências desastrosas para a vida dessas mulheres, como baixa auto-estima, frustrações, revoltas, sentimento de exclusão, que somados a fatores de ordem econômica, como necessidade financeira e falta de oportunidade no mercado de trabalho, resultam negativamente - a reincidência. Essa realidade é mostrada em números: das 33 mulheres que se encontram reclusas, 14 são reincidentes.

Neste momento, consideramos importante retomar o conceito de que a diferenciação é o processo central pelo qual a identidade é produzida. Entretanto, há uma série de processos que podem traduzir essa diferenciação, marcados pelo poder: incluir / excluir "estas mulheres são sociais, aquelas são anti-sociais"; demarcar fronteiras "nós" e "elas"; classificar "mulheres boas e mulheres más"; normalizar "nós somos normais; elas são anormais". Ou seja, não é uma relação simétrica, e elas mesmas se inserem no pólo que recebe carga negativa, provavelmente pelas interações sociais experienciadas na sociedade e no presídio.

É possível observar que elas enfatizam frequentemente a ideia de que "não são bichos". Muitas reclamaram de serem comparadas a animais, como é o caso de Silvana (11), e há até quem expresse uma certa "internalização" dessa identidade, como mostra a fala de Rosa (12), a seguir:

Pensam que nós somos bicho. / Mas não é porque a gente tá aqui que a gente é um bicho de sete cabeças, que não é (Silvana). 
(12)

Um lugar fechado com um monte de grade, muro, você vê assim, um monte de grade assim, trancado igual um bicho, eu me sinto assim, igual um bicho trancado, porque a última vez que eu vi lá o mundo lá fora foi o dia que eu fui assinar minha condenação, não vi mais (Rosa, grifo nosso - indica ênfase na fala da participante)

De acordo com esses depoimentos, percebe-se que, após serem libertadas das grades, continuam aprisionadas pelo estigma social, por isso consideram difícil o retorno à sociedade, principalmente em relação ao trabalho considerado "honesto", pois, para não sofrer discriminação, serem humilhadas ou negadas, voltam-se às "facilidades" do mundo do crime.

Este distanciamento das identidades socialmente valorizadas hegemônicas - faz surgir uma identidade mais próxima do processo de marginalização. Por isso, na visão das participantes, a prisão não recupera ninguém; ao contrário, produz identidades reincidentes, geradas pelo preconceito da sociedade e intensificadas pela experiência na prisão. Para Silvana, a presa "sempre sai pior. $80 \%$ pra pior e $20 \%$ para melhor", pois a falta de projetos voltados à reabilitação da interna contribui com a falta de expectativas para o futuro e, ao mesmo tempo, para o reingresso em práticas desviantes.

Para as participantes, a experiência no contexto prisional é vista de forma negativa; por isso, a reincidência tem mais chances de ocorrer. A não reincidência depende, na opinião das informantes, do esforço individual em querer abandonar a criminalidade, e o esforço individual encontra suas fraquezas em situações desfavoráveis, em suas expectativas inseguras, em seus medos:

(13)

Eu não quero mesmo mais fazer coisa errada, mas, se eu me ver apurada eu vou fazer, eu sei que eu vou fazer ( ) é difícil, é muito difícil a gente falar que vai parar e parar e é por isso que se encontra muita mulher presa, muita menina nova, né, presa por isso. Elas tão no mundo do crime vem e prende e puxa um tempo de cadeia, sai pra rua, daí sai sem aquilo que perdeu, né, porque às vezes tinha a casa montadinha, alguma coisinha, não tem mais nada daquilo, sai com a roupa que tá dentro da cadeia, sai sem nada, então chega lá na rua, ela olha prum lado e pro outro "meu Deus, onde que eu vou?" "eu não tenho uma roupa boa pra mim vestir", é onde que vai pra vida do crime de novo. É difícil, não é fácil (Dona Nanci, grifo nosso - indica ênfase na fala da participante). 
(14)

Parece, assim, que faz tanto tempo que eu estou aqui dentro que parece que eu não sei como que eu vou fazer lá fora. Eu passo o tempo todo preocupada como vou fazer lá fora, que as outras falam assim que quando vai presa a gente não consegue trabalho, a gente fica suja na sociedade, então eu me preocupo muito com isso (Lúcia).

Dona Nanci (13) demonstra a dificuldade vivenciada por ex-presidiárias de se afastarem do comportamento desviante, e Lúcia (14) reflete a preocupação da maioria com o estigma e com o preconceito. Seus pensamentos são permeados de inseguranças, incertezas, medos em relação ao futuro extramuro e em relação ao que encontrarão lá fora e de como a sociedade as receberá.

Mas enquanto estão reclusas, qual será a relação da prisão, enquanto instituição, na (re)constituição das identidades dessas mulheres? De acordo com suas representaçóes, a prisão é um lugar onde não há nada para se fazer, "a não ser ficar uma olhando pra cara da outra", como afirmou Josiani. Por isso, uma das formas que encontraram para passar o tempo é com o artesanato:

Aqui dentro, o que eu puder fazer eu faço pra poder dar pra elas sabe, o dinheiro que eu ganho, eu dou tudo pra elas, o crochê que faço, eu dou tudo pra elas sabe; então tenho orgulho, dou um tapete pra uma, uma coisa pra outra, pra manter aquele amor (Dona Nanci).

Eu passo a maior parte do tempo fazendo crochê. Eu faço tapete, meu marido leva pra fora pra vender (Lúcia).

Eu faço crochê (.) umas fazem carta de metro, outra faz o desenho, umas não fazem nada, ficam assim conversando, umas são manicuras (Silvana).

Elas fazem tapetes de barbante, crochê e trabalhos artesanais, como forma de passar o tempo e obter alguma renda com a venda de seus trabalhos. É certo que conviver em uma prisão é se adequar a novas formas de viver, visto que este ambiente é muito diferente do mundo externo, onde as ações estão voltadas para a produção, o trabalho e o consumo. Nesse contexto, a noção de tempo é ressignificada, sentem-se muito ociosas, dormem até mais tarde, para o tempo passar mais rapidamente. 
Uma outra identidade também surge neste contexto prisional: a de escrevente. A necessidade de encontrar uma ocupação para passar o tempo, o desejo de desabafar, a saudade e a necessidade de interagir com os amigos, namorados, companheiros, filhos e familiares são os principais motivos que as fazem escrever muitas cartas:

A maioria das atividades que tem aqui é escrever, acho que o que as mulheres mais fazem aqui dentro é escrever, escrever o problema que está passando, que não tá (Liliane).

Tem umas ali que não sei como aguentam, é o dia inteiro com caneta e papel na mão, o dia inteiro escreve, a única coisa que sabe fazer, né? Escrever, então fica lá, o dia inteiro escrevendo (Dona Nanci).

(20)

Escrevo que eu tô com saudade, que eu gosto muito, como que eu tô aqui, esse tipo de coisa, eles escrevem pra mim e eu escrevo respondendo. Escrevem que tão com saudade, contam novidade que tá acontecendo com eles, assim que:: sempre alguma amiga escreve, porque na rua eu conversava muito, dava conselho, daí ela escreve "ah, briguei com meu namorado", "briguei com meu marido" por causa disso, disso e disso, daí eu escrevo de volta "ah, tem que ter paciência" (Taís).

Podemos relacionar a prática da escrita no presídio feminino com a carência, com o sentimento, com a saudade, com a afeição, com a necessidade dessas mulheres em se comunicar com quem amam. A escrita, considerada um importante meio de interação com o mundo, tem papel fundamental para a constituição e, ao mesmo tempo, manutenção das identidades dessas mulheres, no sentido de ajudá-las a manter o contato com o mundo externo, a manter o laço afetivo e continuar desempenhando sua identidade de mãe, de filha, de amiga, de mulher.

Por isso, a escrita adquire uma função social em suas vidas e contribui para o bem-estar que sentem quando recebem a carta de alguém ou quando utilizam a escrita para se expressar ou desabafar, podendo deixar um pouco de suas angústias em um pedaço de papel.

Além de poderem se expressar, há quem utilize a escrita como uma forma de trabalho. Rebeca, uma das internas, confecciona cartas de metro e cobra por número de folhas. Geralmente, quando suas colegas de cela querem 
presentear alguém com uma mensagem, encomendam a carta, que é escrita por Rebeca e ilustrada por Eliene. A seguir apresentamos um trecho de uma das cartas escritas por Rebeca:

"Que barra" numa cela, hoje me encontro, restrita a liberdade, pagando por um erro que cometi. Me tiraram o direito de ir e vir. Mas, sou livre para pensar, livre para relembrar, livre para sonhar... E agradeço a você, é você mesmo; que está lendo esta mensagem agora, pois, você, mesmo sem querer me concedeu uma "pitada" de liberdade, estou livre para dizer a você o que penso... (Rebeca).

É um exemplo de que essa situação de exclusão e a necessidade podem levar à busca de novas atividades. Por isso, na prisão, tornam-se escreventes em potencial, pois a escrita faz com que se sintam parte da sociedade, é a representação de sua existência e de sua subjetividade enquanto mulher que está em uma prisão, mas que ainda tem o que dizer e o que expressar, em especial para os familiares.

No caso de Rebeca, além de a escrita ser um trabalho e um meio de obter algum dinheiro, percebemos, através da leitura de suas cartas, que a linguagem é uma forma de libertação, é uma maneira que ela encontrou para desabafar, reclamar, extravasar seus pensamentos, medos e receios. A escrita é um instrumento de fuga de sua atual realidade, contribuindo para amenizar os sentimentos ruins gerados em virtude da reclusão. Provavelmente, Rebeca é a mais livre das mulheres do presídio. Ela "está presa", ela "não é presa".

Por meio das análises realizadas, foi possível observar que a prisão pode (re)constituir, (re)construir, transformar e marcar as representaçôes e identidades sociais das pessoas que nela estão inseridas. Nesse caso, geralmente, as identidades são marcadas com um traço negativo, doloroso e triste. Mas, quando se referem aos seus projetos futuros, as mulheres que estão encarceradas tentam constituir uma identidade idealizada na esperança e fé na vida. Acreditar é o primeiro passo, segundo elas:

Pretendo acho que vim morar aqui em Maringá. / Arrumar um serviço que é o que eu quero. / Ah, meus filhos continuarem estudando, que uma coisa que eu não quero pra eles é que eles parem de estudar. / Eu vou tentar voltar a estudar novamente, o meu sonho é fazer faculdade. O meu sonho é fazer Direito ainda e eu vou correr atrás dele (Paula).

(23) Quero começar a construir de novo a minha fábrica, que é uma 
coisa que eu posso trabalhar na minha casa, eu posso dar emprego pra alguém e posso amanhã ou depois ser alguém na vida sem estar mexendo com coisa errada, tudo o que eu quero é fazer isso (Dona Nanci).

Em primeiro lugar, eu quero casar com meu esposo, que nós não somos casados, depois eu quero ser batizada na igreja crente, fazer minha cirurgia e arrumar um trabalho (Lúcia).

Quem teve preso tá precisando de ajuda, de algum trabalho. / Eu quero pedir pra ele (juiz) me ajudar, pra ver se eu consigo um emprego, e eu sou uma pessoa assim que eu vou muito atrás do que eu quero e se eu me dei bem vendendo droga, eu posso me dar bem vendendo outra coisa (Taís).

Quando eu sair daqui eu quero arrumar um trabalho, arrumar minha casa, comprar meus móveis tudo de novo, que eu perdi, conseguir meu filho de novo e começar uma nova vida, é isso que eu quero (Josiani).

Eu tenho fé em Deus que logo tô indo embora pra cuidar do meu filho (Rosa).

Eu pretendo trabalhar honestamente, porque eu já trabalhava honestamente antes, cuidar da minha vida. / Eu ainda pretendo fazer mais dois anos de estudo e fazer enfermagem (Silvana).

Quero fazer uma faculdade de gastronomia e trabalhar com meu cunhado, que é administrador de empresa, ele quer que eu trabalhe com ele na empresa dele e eu vou trabalhar, trilhar novos caminhos pra minha vida (Julia).

Pretendo mudar (.) mudar bastante, cuidar da minha filha, do meu vô (Graciela).

Quando eu sair daqui eu vou voltar a morar com a minha mãe, porque eu perdi tudo, eu quero construir tudo de novo, quero arrumar um emprego decente, quero fazer um curso, quero continuar meus estudos, quero ter a minha casa, dar uma vida melhor pros meus filhos, 
é isso que eu penso hoje, mostrar pra eles que tudo isso que eu passei, não quero que eles passem jamais na vida deles (Liliane).

Essas declarações parecem mostrar as representações de felicidade ou de vida "normal" para essas mulheres. Embora esteja em descompasso com as representações negativas que elas possuem da sociedade e do que podem encontrar depois que as grades da prisão forem abertas, há em seus planos a esperança de que tudo pode ser diferente. Seus sonhos, baseados em representações hegemônicas, são construídos a partir de identidades e construçôes sociais aceitas e reconhecidas pela sociedade, da identidade de pessoa que cometeu ato desviante e que se compromete a mudar e trilhar o caminho do bem, do socialmente valorizado: cuidar dos filhos, cuidar da casa, constituir família, trabalhar, mudar de vida, se afastar do mundo do crime, estudar, fazer faculdade.

Enfim, as mulheres que estão em conflito com a lei reafirmam representaçôes e identidades de gênero muitas vezes hegemônicas, o que gera conflitos de identidade a partir de suas realidades culturais, decorrentes de sua classe social, de sua estrutura familiar, de sua baixa escolaridade e do estigma que levarão como ex-presidiárias.

\section{Considerações finais}

Os dados deste trabalho mostram algumas das identidades sociais de gênero negociadas, desejadas e/ou negadas pelas participantes e possíveis conflitos de identidade gerados pelo contraste entre as construções sociais hegemônicas e aceitas socialmente e a realidade vivenciada pelas mulheres em conflito com a lei.

Ao ter oportunidade de conhecer essas mulheres e o contexto de reclusão no qual estão inseridas, constata-se a carência e a necessidade. Dentre as várias possibilidades que se colocam a frente, poderiam ser desenvolvidos projetos voltados ao resgate da leitura e da escrita, por meio da motivação e adequação desta prática a várias funções sociais dentro do presídio. Poderiam ser realizados vários projetos voltados à reinserção dessas mulheres, a partir da educação não formal, na qual mediadores poderiam trabalhar a leitura e a escrita, através de uma concepção de letramento em termos de prática e eventos sociais, priorizando aspectos sociais de suas vidas, dando condiçôes para que as mulheres que estão reclusas, nesse presídio feminino, possam inserir-se dignamente em uma sociedade letrada. 
Acreditamos que a prisão não deva ser espaço a partir do qual as pessoas fiquem marcadas pelo estigma de presidiárias, mas deve ser um espaço voltado para a reabilitação e reinserção social, por meio de atividades planejadas para cada grupo social. Ou seja, um espaço para a aplicação da inclusão, e não da exclusão, por meio da escrita, por exemplo, que pode ser percebida como constituinte na vida de pessoas socialmente excluídas, e não como um traço que é de um grupo social privilegiado e que precisa ser adquirido para "ser alguém na vida" (SIGNORINI, 1994). Elas estão passando por processos de ressignificação de algumas representações sociais e conflitos de identidade, os quais precisariam ser trabalhados não para impor-lhes as representações hegemônicas, mas no sentido de torná-las mais conscientes de quais são suas representaçôes e identidades e de que forma as oprimem.

\section{Referências}

ANDRADE, M. A. A. A identidade como representação e a representação da identidade. In: MOREIRA, A. S. P; OLIVEIRA, D. C. (Org.). Estudos interdisciplinares de representação social. Goiânia: AB, 2000.

AUAD, D. Educar meninas e meninos: relações de gênero na escola. São Paulo: Contexto, 2006.

BAKHTIN, M. Marxismo e filosofia da linguagem. São Paulo: Hucitec, 1981.

ERICKSON, F. Métodos cualitativos de investigación sobre la enseñanza. In: WITTROCK, M. C. La investigación de la enseñanza, II: métodos cualitativos y de observación. Barcelona: Ediciones Pidós, 1989.

ESPINOZA, O. A mulher encarcerada em face do poder punitivo. São Paulo: IBCCrim, 2004.

FOUCAULT, M. Vigiar e punir. Petrópolis, Vozes, 1977.

HALL, S. A identidade cultural na pós-modernidade. Rio de Janeiro: DP\&A Editora, 2000.

HALL, S. Quem precisa da identidade? In: SILVA, T. T. (Org.). Identidade e diferença - a perspectiva dos estudos culturais. Petrópolis, RJ: Vozes, 2007.

JODELET, D. Representações Sociais: Um domínio em expansão. In: JODELET, D. (Org.). As Representaçôes Sociais. Rio de Janeiro: Ed. UERJ, 2001. LOURO, G. L. Gênero, sexualidade e educação. Uma perspectiva pósestruturalista. 2. ed. Petrópolis, RJ: Vozes, 1998. 
MEYER, D. E. Gênero e educação: teoria e política. In: LOURO, G. L.; FELIPE, J. F.; GOELLNER, S. V. (Org.). Corpo, gênero e sexualidade. Um debate contemporâneo na educação. Petrópolis, RJ: Vozes, 2007.

MOITA LOPES, L. P. da. Contextos institucionais em Linguística Aplicada: novos rumos. In: Intercâmbio, v. 5, p. 3-14, 1996. Disponível em: <www. leffa.pro.br/textos/Moita_Lopes.pdf>. Acesso em: 17 abr. 2008.

MOITA LOPES, L. P. da. Identidades fragmentadas. A construção discursiva de raça, gênero e sexualidade em sala de aula. Campinas, SP: Mercado de Letras, 2002.

MOKI, M. P. Representações sociais do trabalho carcerário feminino. $2005.218 \mathrm{f}$. Dissertação (Mestrado em Ciências Sociais). Universidade Federal de São Carlos, São Paulo, 2005.

MOSCOVICI, S. As representaçôes sociais da psicanálise. Rio de Janeiro: Zahar, 1981 .

MOSCOVICI, S. Prefácio. In: GUARESCHI, P. A.; JOVCHELOVITCH, S. (Org.). Textos em Representações Sociais. Petrópolis, RJ: Vozes, 1997.

SIGNORINI, Inês . A letra dá vida mas também pode matá: os sem leitura diante da escrita. Leitura. Teoria \& Prática, Campinas, v. 13, p. 20-27, 1994.

SIGNORINI, Inês. A questão da língua legítima na sociedade democrática: um desafio para a Linguística Aplicada contemporânea. In: MOITA LOPES, L. P. da (Org.). Por uma Linguística Aplicada indisciplinar. São Paulo: Parábola Editorial, 2006.

SILVA, T. T. (Org.). Identidade e diferença - a perspectiva dos estudos culturais. Petrópolis, RJ: Vozes, 2007.

WOODWARD. K. Identidade e diferença: uma introdução teórica e conceitual. In: SILVA, T. T. (Org.). Identidade e diferença - a perspectiva dos estudos culturais. Petrópolis, RJ: Vozes, 2007.

Recebido em março de 2009. Aprovado em junho de 2009 